\title{
Bronchial and extrabronchial factors in chronic airflow obstruction
}

\author{
D. G. LEAVER, A. E. TATTER FIELD, and N.B. PR IDE \\ Department of Medicine, Royal Postgraduate Medical School, Hammersmith Hospital, London W12
}

\begin{abstract}
Leaver, D. G., Tattersfield, A. E., and Pride, N. B. (1974). Thorax, 29, 394-400. Bronchial and extrabronchial factors in chronic airflow obstruction. Chronic airflow obstruction may be due either to disease of the airway wall and lumen or to loss of airway-distending forces acting on the outer wall of the bronchus. In 17 patients with chronic airflow obstruction the relative importance of bronchial and extrabronchial factors was assessed by analysing the relation between airways conductance and static transpulmonary pressure over a range of lung volumes. Using previously established clinical, radiological, and functional criteria (which did not include measurements of the mechanical properties of the lungs), six of these patients had evidence of widespread emphysema and six patients had predominant 'bronchial' disease. In four of the six 'emphysematous' patients there was no functional evidence of disease of the bronchial wall or lumen during quiet breathing, and airway narrowing could be explained by loss of airway-distending forces. The six patients with characteristic 'bronchial' features showed functional evidence of disease of the bronchial wall or lumen.
\end{abstract}

In 1955 Dornhorst described two contrasting types of patient with chronic irreversible airways obstruction-the first characterized by disabling breathlessness without cyanosis or tendency to heart failure ('pink and puffing') and the second in whom the clinical picture was dominated by cyanosis and recurrent right heart failure ('blue and bloated'). Subsequently numerous clinical and physiological studies have confirmed this broad distinction (Ogilvie, 1959; Richards, 1960; Fletcher, HughJones, McNicol, and Pride, 1963; Mitchell, Vincent, Ryan, and Filley, 1964; Briscoe and Nash, 1965). On the basis of an extensive clinicopathological study, Burrows et al. (1966) proposed that these two contrasting presentations of chronic airways obstruction could be regarded as respectively the 'emphysematous' and the 'bronchial' types of airway obstruction. In their study the distinction between these two types in life was based on clinical and radiological features and three tests of pulmonary function (CO transfer factor by the single breath method, total lung capacity, and the arterial carbon dioxide pressure), none of which was a direct measurement of airflow obstruction. Recently we have analysed the contributions of disease of the bronchial wall and lumen and of loss of extrabronchial distending forces to the airway narrowing of 17 patients with chronic airflow obstruction (Leaver, Tattersfield, and Pride, 1973). It might be anticipated that these two contrasting mechanisms of airway narrowing would be characteristic of 'bronchial' and 'emphysematous' disease respectively. In the present paper we have used the criteria of Burrows et al. (1966) to classify the patients in our previous study into subgroups with marked 'bronchial' and 'emphysematous' features and have examined whether there are differences in the mechanisms of airflow obstruction between these two subgroups.

\section{MATERIAL AND METHODS}

PATIENTS STUDIED AND CLINICAL AND PHYSIOLOGICAL TECHNIQUES Seventeen patients (16 men and 1 woman, average age 61.4 years) with chronic airflow obstruction $\Omega$ were studied. The forced expiratory volume in one second $\mathrm{N}$ $\left(F_{1}\right)$ varied between 0.4 and 1.7 litres, with a mean of $\mathrm{N}$ 1.02 litres. All the patients had chronic cough and ex- $\omega$ pectoration, were present or ex-smokers, and had been under medical observation for at least two years during 0 which time there had been little variation in their airflow obstruction either spontaneously or after treatment. Ten $\stackrel{\mathscr{S}}{+}$ normal subjects ( 9 men and 1 woman, average age 34.57 years) were studied using the same methods. Only two $\bar{O}$ of these subjects were cigarette smokers, none had any respiratory symptoms, and in all spirometry and the chest radiographs were normal.

Heart failure was diagnosed if oedema was accompanied $\underset{\gamma}{\sigma}$ by a raised jugular venous pressure. Sputum volumes 
were assessed by collections made in the first hour after waking. The radiological diagnosis of emphysema was based on the presence of widespread attenuation of the smaller pulmonary vessels and was made by one radiologist. The $\mathrm{FEV}_{1}$ was measured with a dry spirometer with automatic timer. The transfer factor for CO (TFCO) was measured by the single breath technique (Ogilvie, Forster, Blakemore, and Morton, 1957) and results were also expressed as transfer factor per litre lung volume (TF/VA). In calculating this ratio lung volume was expressed in litres of dry gas at standard temperature and pressure. Mixed venous carbon dioxide pressure $\left(\mathrm{P}_{\overline{\mathrm{vCO}}}\right)$ was measured by the rebreathing method (Campbell and Howell, 1962); the $\mathrm{P}_{\bar{v}} \mathrm{CO}_{2}$ predicted from the $\mathrm{FEV}_{1}$ was derived from the formula of Burrows, Strauss, and Niden (1965): $\mathrm{P}_{\bar{C} \mathrm{CO}_{2}}(\mathrm{mmHg})=11 \cdot 5 / \mathrm{FEV}_{1}+36 \cdot 7$, where $\mathrm{FEV}_{1}$ is expressed in litres. Total lung capacity (TLC) was measured in a constant-volume body plethysmograph (DuBois et al., 1956a). Airways conductance was measured in the plethysmograph by the panting technique (Dubois, Botelho, and Comroe, 1956b) at a variety of lung volumes; at each lung volume conductance was measured at an inspiratory flow rate of 0.5 litre $\mathrm{sec}^{-1}$. Static transpulmonary pressure (difference between mouth and oesophageal pressure) was measured by the oesophageal balloon technique. A balloon volume of $0.5 \mathrm{ml}$ was used and static expiratory pressure-volume curves were obtained after a standard volume history of three full inflations (Milic-Emili, Mead, Turner, and Glauser, 1964). From these measurements at different lung volumes a conductance-static transpulmonary pressure plot was constructed for each patient. A line of best fit was drawn by eye to obtain the slope ( $\Delta$ conductance/ $\Delta$ static transpulmonary pressure) of this plot. Static lung compliance was taken as the slope of the expiratory transpulmonary pressure-volume curve between the resting expiratory level (functional residual capacity, FRC) and $500 \mathrm{ml}$ above FRC. Normal values of FEV 1 , TFCO, and TLC were obtained from the nomograms published by Cotes (1968).

SUBDIVISION OF PATIENTS INTO 'EMPHYSEMATOUS', 'BRONCHIAL' AND INDETERMINATE SUBGROUPS The 17 patients were divided into those with type A disease ('emphysematous'), type B (absent or mild emphysema and marked 'bronchial' features), and type $\mathrm{X}$ disease (indeterminate) by clinical, radiological, and functional criteria similar to those used by Burrows et al. (1966). Type A disease was diagnosed if the chest radiograph showed widespread attenuation of the peripheral vascular pattern. Type B disease was diagnosed when there was no radiological evidence of emphysema and there were in addition at least two (and usually three) of the following features: (1) persistent expectoration of $5 \mathrm{ml}$ or more of sputum in the first hour; (2) $\mathrm{P}_{\overline{\mathrm{VCO}}} 6 \mathrm{mmHg}$ or more above the level predicted from the FEV 1 ; (3) TF/VA over 3.50; (4) chronic or recurrent heart failure due to persistent cor pulmonale. Patients who could not be classed as either type A or type B by these criteria were classed as type X. Two criteria used for this subdivision by Burrows et al. were not used in the current study-radiographic evidence of chronic inflammatory disease in the lung parenchyma (which was not observed in any of the 17 patients) and a total lung capacity less than $100 \%$ of the predicted value. In the present series, total lung capacity was measured by the body plethysmograph method, which gives larger values in patients with severe airflow obstruction than the gas dilution methods used by Burrows et al., and only one patient had a value below that predicted. One other criterion was slightly modified, a sputum volume of $5 \mathrm{ml}$ or more in the first hour collection being taken as equivalent to a volume of $10 \mathrm{ml}$ or more over 24 hours (Miller, Tinker, and Fletcher, 1965).

ANALYSIS OF MECHANISM OF AIRFLOW OBSTRUCTION Airway calibre is determined by the interplay of the intrinsic properties of the airway wall and lumen and the extrinsic forces acting across the wall tending to distend or compress it. During quiet breathing these extrinsic forces will distend the airway. Hence airway narrowing may be caused either by intrinsic obstruction of the airway (defined as a reduced airway lumen at a standard airway distending pressure) or by loss of airway-distending forces (Dayman, 1951).

To distinguish between these two forms of airflow obstruction in life it is necessary to examine the relationship between airway size and airway-distending pressures. An overall indication of the size of the airways can be obtained by measuring airways conductance (the reciprocal of airways resistance) at low flow rates in the body plethysmograph. The value of conductance potentially provides a sensitive estimate of airway radius, since the conductance of a tube is proportional to the fourth power of its radius. Airway-distending pressures cannot be estimated so directly but theoretical and experimental studies (Butler, Caro, Alcala, and DuBois, 1960; Mead, Takishima, and Leith, 1970; Stubbs and Hyatt, 1972) indicate that during breath-holding or breathing at low flow rates the pressure distending the intrathoracic airways is probably similar to the pressure distending thelung as a whole, which is static transpulmonary pressure. Therefore by relating airways conductance (indicating overall airway dimensions) to static transpulmonary pressure (indicating airway-distending forces) it is possible to demonstrate whether airway narrowing is due to loss of airway-distending forces or to disease of the bronchial wall or lumen itself. In practice it is preferable to measure this relationship over a range of lung volumes and to obtain the value of $\Delta$ conductance $/ \Delta$ static transpulmonary pressure (Fig. 1) rather than to rely on values close to FRC where absolute differences in conductance with contrasting mechanisms of airflow obstruction will be smaller. $\Delta$ conductance $/ \Delta$ static transpulmonary pressure is in some ways analogous to a measurement of airway distensibility and will be reduced if individual airways are stiff and indistensible. However, $\Delta$ conductance $/ \Delta$ static transpulmonary pressure will also be reduced if there is a reduction in the total number of open airways, or if primary airway disease leads to an overall reduction in airway diameters. Hence a reduced $\Delta$ conductance $/ \Delta$ static transpulmonary pressure indicates disease of the bronchial wall or lumen itself. In contrast, a normal value of $\Delta$ conductance $/ \Delta$ static transpulmonary pressure will 


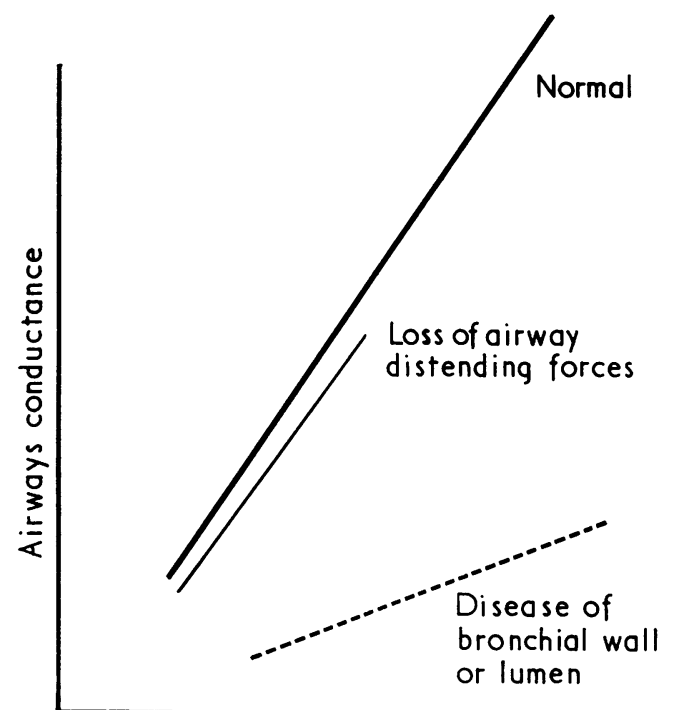

Static transpulmonary pressure

FIG. 1. Theoretical relationship between airways conductance and static transpulmonary pressure. Disease of the bronchial wall or lumen reduces conductance at any given value of static transpulmonary pressure and also reduces the slope, $\Delta$ conductance/D static transpulmonary pressure. With loss of airway-distending forces conductance remains normal for the value of transpulmonary pressure and $\Delta$ conductance/ $\Delta$ static transpulmonary pressure is unchanged.

be found when airway narrowing is caused solely by a reduction in extrabronchial forces distending the airways.

\section{RESULTS}

The mean results of the standard tests of pulmonary function in the 17 patients are shown in Table $I$. The expected increase in total lung capacity and reduction in transfer factor were observed and the average mixed venous $\mathrm{PCO}_{2}$ was very close to that predicted.
The 10 normal subjects had an average height of $\underset{\vec{S}}{\stackrel{\vec{S}}{+}}$ 1.77 metres; mean $\mathrm{FEV}_{1}$ was 4.15 litres $(109 \%$ of the predicted value) and mean TLC was 7.33 litres $\frac{0}{0}$ (106\% of the predicted value). Transfer factor and $\frac{\bar{c}}{\mathrm{~m}}$ mixed venous $\mathrm{PCO}_{2}$ were not measured in the normal subjects.

SUBDIVISION INTO 'EMPHYSEMATOUS', 'BRONCHIAL', 굴 AND INDETERMINATE SUBGROUPS Six patients were $\vec{\omega}$ placed in the 'emphysematous' group on the basis $\odot$ of widespread vascular attenuation on the chest $\vec{x}$ radiograph. In all of them total lung capacity was i़ greater than $120 \%$ of the predicted value, transfer factor per litre of lung volume was less than $1.40 \omega$

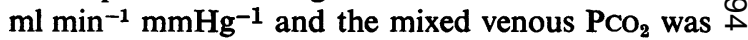
less than predicted from the $\mathrm{FEV}_{1}$. Six patients 읏 fulfilled the criteria for the 'bronchial' group. Mean values of $\mathrm{FEV}_{1}$ in these two subgroups were identical $\subseteq$ but there were large differences in transfer factor and mixed venous $\mathrm{PCO}_{2}$ levels, and a smaller differ- $\overrightarrow{0}$ ence in total lung capacity (Table I). These differences $\perp$ correspond to those described previously (Burrows et al., 1966). The remaining five patients, placed in the indeterminate subgroup, were smaller than those in the other subgroups and had somewhat less severe reduction of the $\mathrm{FEV}_{1}$.

TESTS OF PULMONARY MECHANICS Table II shows the results of tests of pulmonary mechanics in the normal subjects and the patients with airflow obstruction. As expected, the patients with chronic airflow obstruction had lower values of conductance and higher values of static lung compliance at functional residual capacity than the normal subjects.

Static lung compliance was greater in the 'emphysematous' than in the 'bronchial' subgroup, but the of differences were small. Expiratory pressure-volume $₹$ curves in the 'emphysematous' patients tended to be 윽 displaced to higher volumes and lower transpulmon- $D$ ary pressures than in the 'bronchial' patients but

T A B L E I

MEAN VALUES OF STANDARD TESTS OF PULMONARY FUNCTION IN 'EMPHYSEMATOUS', 'BRONCHIAL' AND INDETERMINATE SUBGROUPS

\begin{tabular}{|c|c|c|c|c|c|c|c|c|c|c|c|c|}
\hline \multirow{2}{*}{ Group } & \multirow{2}{*}{ No. } & \multirow{2}{*}{$\begin{array}{l}\text { Age } \\
(y r)\end{array}$} & \multirow{2}{*}{$\begin{array}{l}\text { Height } \\
\text { (m) }\end{array}$} & \multicolumn{2}{|c|}{ FEV $_{1}$} & \multicolumn{2}{|c|}{$\begin{array}{c}\text { Total Lung } \\
\text { Capacity }\end{array}$} & \multicolumn{3}{|c|}{ Transfer Factor } & \multicolumn{2}{|c|}{$\begin{array}{c}\text { Mixed Venous } \\
\mathrm{PCO}_{2}\end{array}$} \\
\hline & & & & Litres & $\%$ Pred. & Litres & $\%$ Pred. & $\mathrm{ml} \underset{\mathrm{min}^{-1}}{\operatorname{mm} \mathrm{g}^{-1}}$ & $\%$ Pred. & TF/VA* & $\begin{array}{c}\text { Absolute } \\
\text { Value } \\
\text { (mmHg) }\end{array}$ & $\begin{array}{c}\text { Deviation } \\
\text { from Pred. } \\
\text { (mmHg) }\end{array}$ \\
\hline $\begin{array}{l}\text { 'Emphysematous' } \\
\text { 'Bronchial' } \\
\text { Indeterminate }\end{array}$ & $\begin{array}{l}6 \\
6 \\
5\end{array}$ & $\begin{array}{l}62 \cdot 7 \\
57 \cdot 2 \\
64 \cdot 8\end{array}$ & $\begin{array}{l}1 \cdot 69 \\
1 \cdot 71 \\
1 \cdot 61\end{array}$ & $\begin{array}{l}0 \cdot 98 \\
0 \cdot 98 \\
1 \cdot 10\end{array}$ & $\begin{array}{l}36 \\
33 \\
46\end{array}$ & $\begin{array}{l}8 \cdot 05 \\
7 \cdot 18 \\
7 \cdot 24\end{array}$ & $\begin{array}{l}132 \\
115 \\
136\end{array}$ & $\begin{array}{r}5 \cdot 0 \\
12 \cdot 3 \\
10 \cdot 4\end{array}$ & $\begin{array}{l}21 \\
37 \\
46\end{array}$ & $\begin{array}{l}1 \cdot 00 \\
3 \cdot 08 \\
2 \cdot 36\end{array}$ & $\begin{array}{l}43 \cdot 8 \\
58 \cdot 5 \\
47 \cdot 6\end{array}$ & $\begin{array}{r}-8.5 \\
+9.5 \\
-0.4\end{array}$ \\
\hline All patients & 17 & $61 \cdot 4$ & $1 \cdot 67$ & $1 \cdot 02$ & 38 & $7 \cdot 51$ & 127 & $9 \cdot 0$ & 37 & $2 \cdot 14$ & $50 \cdot 1$ & +0.2 \\
\hline
\end{tabular}

*TF/VA = Transfer factor for $\mathrm{CO}\left(\mathrm{ml} \mathrm{mmHg}^{-1} \mathrm{~min}^{-1}\right)$ per litre lung volume. 
T A B L E I I

MEAN VALUES OF MEASUREMENTS OF PULMONARY MECHANICS

\begin{tabular}{|c|c|c|c|c|}
\hline & No. & $\begin{array}{c}\text { Static Compliance } \\
\text { at Functional Residual } \\
\text { Capacity } \\
\left.\text { (litre } \mathrm{cmH}_{\mathbf{2}} \mathrm{O}^{-1}\right)\end{array}$ & $\begin{array}{c}\text { Conductance } \\
\text { at Functional Residual } \\
\text { Capacity } \\
\text { (litre } \sec ^{-1} \mathrm{cmH}_{2} \mathrm{O}^{-1} \text { ) }\end{array}$ & $\frac{\Delta \text { Conductance }}{\Delta \text { Static Transpulmonary }}$ \\
\hline $\begin{array}{l}\text { Normal subjects } \\
\text { Chronic airflow obstruction } \\
\text { A 'Emphysematous' } \\
\text { B 'Bronchial' } \\
\text { X Indeterminate } \\
\text { P value }(A \vee \text { B) }\end{array}$ & $\begin{array}{r}10 \\
17 \\
6 \\
6 \\
5\end{array}$ & $\begin{array}{c}0.30 \\
( \pm 0.02) \\
0.44 \\
( \pm 0.05) \\
0.51 \\
( \pm 0.11) \\
0.43 \\
( \pm 0.09) \\
0.36 \\
( \pm 0.03) \\
\text { N.S. }\end{array}$ & $\begin{array}{c}0.83 \\
( \pm 0.11) \\
0.27 \\
( \pm 0.03) \\
0.33 \\
( \pm 0.04) \\
0.20 \\
( \pm 0.03) \\
0.29 \\
( \pm 0.06) \\
<0.05,>0.01\end{array}$ & $\begin{array}{c}0.111 \\
( \pm 0.013) \\
0.066 \\
( \pm 0.012) \\
0.100 \\
( \pm 0.024) \\
0.038 \\
( \pm 0.008) \\
0.060 \\
( \pm 0.018) \\
<0.05,>0.01\end{array}$ \\
\hline
\end{tabular}

Figures in parentheses indicate 1 standard error of the mean.

there was considerable overlap and only one of the 'bronchial' patients had a pressure-volume curve entirely within the normal range (Fig. 2).

Values of conductance at functional residual capacity in the 'emphysematous' patients were significantly higher than in the patients with 'bronchial' features, although in both groups mean values were below the lower limit of normal $(0.4$ litre $\left.\mathrm{sec}^{-1} \mathrm{cmH}_{2} \mathrm{O}^{-1}\right)$. The value of $\Delta$ conductance/ $\Delta$ static transpulmonary pressure was within the normal range in four of the six 'emphysematous' patients and the mean value for this 'emphysematous' group as a whole was only slightly below that found in the normal subjects. Values of $\Delta$ conductance/ $\Delta$ static transpulmonary pressure were reduced in the

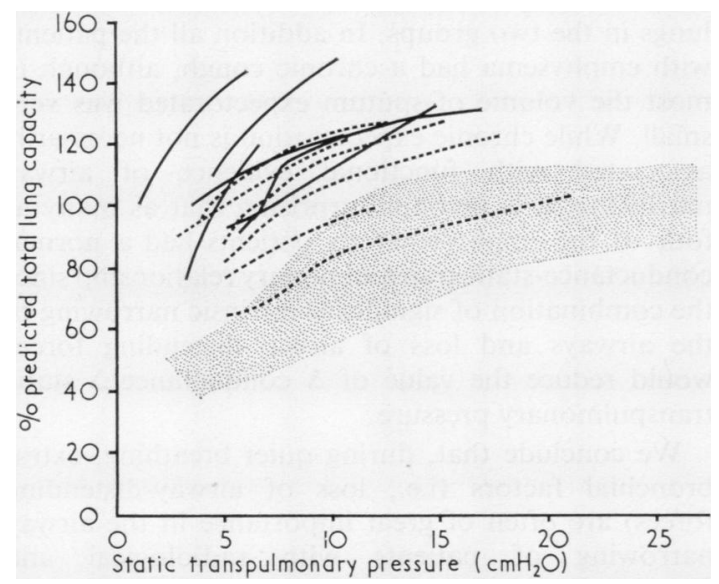

FIG. 2. Expiratory static transpulmonary pressure plotted against lung volume (expressed as $\%$ of predicted total lung capacity). Continuous lines show the curves of the six 'emphysematous' patients, and the interrupted lines the curves of the six 'bronchial' patients. Hatched area shows the range of the curves in 10 normal subjects. 'bronchial' group. Two of the five indeterminate patients had normal values of $\Delta$ conductance/ $\Delta$ static transpulmonary pressure.

\section{DISCUSSION}

In 1951 Dayman first suggested that two different processes-intrinsic obstruction of the airway lumen and loss of airway-distending forces-were likely to be important in airflow obstruction. Although he equated these two contrasting types of obstruction with asthma and emphysema respectively, the 'bronchial' type of airflow obstruction could also be expected to be caused by intrinsic obstruction. These two causes of airway narrowing can be distinguished by measuring the change in conductance as transpulmonary pressure is increased because the value of $\Delta$ conductance/ $\Delta$ static transpulmonary pressure remains normal with loss of airway distending forces but is reduced when there is intrinsic obstruction. In the present study four of the six patients with evidence of widespread emphysema had normal values of $\Delta$ conductance $/ \Delta$ static transpulmonary pressure so that in them abnormalities in conductance could be explained by loss of airway-distending forces without any need to postulate additional disease of the bronchial wall or lumen. In contrast, the six patients in the 'bronchial' subgroup had an abnormal conductance-transpulmonary pressure relationship, indicating the presence of abnormality of the bronchial wall or lumen. Although our normal subjects were considerably younger than the patients, there appears to be no change in conductance at the resting breathing level (Butler et al., 1960) or in $\Delta$ conductance/ $\Delta$ static transpulmonary pressure (Colebatch, Finucane, and Smith, 1973) with increasing age, so this difference should not have influenced our results. 
In 1960 Butler et al. described changes in the value of $\Delta$ conductance/ $\Delta$ static transpulmonary pressure in patients with chronic airflow obstruction but they did not use this technique to distinguish different mechanisms underlying chronic airflow obstruction. Recently, Colebatch et al. (1973) have found nearly normal conductance-static transpulmonary pressure curves (obtained by a different method) in patients with radiological evidence of emphysema but without chronic expectoration. These authors also state that in further unpublished experiments they found reduced values of $\Delta$ conductance/ $\Delta$ static transpulmonary pressure in patients with clinical evidence of bronchitis. Several other workers have distinguished an 'emphysematous' type of airflow obstruction on the basis of a normal value of conductance at the resting breathing level (Stevens, Orman, and Graves, 1969; Duffell, Marcus, and Ingram, 1970; Penman, O’Neill, and Begley, 1970). This criterion will underestimate the number of patients in whom loss of airway-distending forces can account for the airflow obstruction, since if static transpulmonary pressure is reduced at functional residual capacity, airways conductance will also be reduced. Only two of our emphysematous patients had values of conductance at the resting breathing level at or just above the lower limit of the normal range $\left(0.4\right.$ litre $\mathrm{sec}^{-1} \mathrm{cmH}_{2} \mathrm{O}^{-1}$, equivalent to an airways resistance of $2.5 \mathrm{~cm} \mathrm{H}_{2} \mathrm{O}$ litre ${ }^{-1} \mathrm{sec}$ ), whereas four of them had normal values of $\Delta$ conductance $/ \Delta$ static transpulmonary pressure. Hence we prefer to measure the conductance $/ \Delta$ static transpulmonary pressure slope to distinguish airway narrowing due to loss of airway-distending forces.

In assessing the significance of these results, three important qualifications need to be made. First, although reductions in airway conductance during quiet breathing in emphysematous patients often can be accounted for by reductions in static transpulmonary pressure, this does not establish that the airways in these patients are anatomically normal. Considerable pathological changes can be present in the more peripheral airways without total airways conductance being greatly affected, because the larger airways play the major part in determining the value of conductance (Hogg, Macklem, and Thurlbeck, 1968). Nevertheless recent morphological studies have shown that there are only slight alterations in the number and diameters of small airways (less than $2 \mathrm{~mm}$ internal diameter) in emphysematous lungs when compared to control lungs fixed at a similar transpulmonary pressure (Matsuba and Thurlbeck, 1972).

Second, the present analysis of airway dimensions only applies during static or near-static conditions.
The finding that the $\mathrm{FEV}_{1}$ was similar in the 'emphy- $\overrightarrow{\mathrm{F}}$ sematous' and 'bronchial' subgroups, despite differ- $-\overrightarrow{0}$ ences in conductance measured at low flow rates, $\frac{C}{0}$ indicates that during forced expiration additional $\overline{\bar{c}}$ dynamic factors were contributing to the expiratory $\overparen{\Phi}$ obstruction in the emphysematous patients. Although $\frac{\circ}{2}$ loss of static transpulmonary pressure will itself के reduce maximum flow rates from the lung (Mead, $\overrightarrow{0}$ Turner, Macklem, and Little, 1967; Pride, Permutt, $\vec{\overrightarrow{ }}$ Riley, and Bromberger-Barnea, 1967) in all the $\vec{\sigma}$ emphysematous patients maximum flow was reduced $\stackrel{\vec{F}}{\vec{F}}$ more than could be accounted for directly by loss of $\vec{x}$ static transpulmonary pressure. The contribution of dynamic airway narrowing to airflow obstruction is discussed in detail elsewhere (Leaver et al., 1973).

Third, there is often evidence of bronchial disease as well as a reduction in static transpulmonary pressure in an individual patient. In the present series $\vec{c}$ we attempted deliberately to contrast subgroups with strongly 'emphysematous' or 'bronchial' features $\overrightarrow{0}$ in order to study different mechanisms of airflow obstruction. Many patients cannot be placed in either of these subgroups; even when the criteria are fulfilled, complete separation of 'emphysematous' and 'bronchial' features is often not obtained. Two of the patients in the 'bronchial' group had total lung capacities of $125 \%$ of the predicted value, $\stackrel{\varnothing}{\circ}$ reduced transfer factor, and markedly increased $\overrightarrow{\overrightarrow{0}}$ static lung compliance, suggesting that they also 3 had some emphysema which was not detected on the chest radiograph. These two patients largely account for the failure to obtain a clearer distinction between the pressure-volume characteristics of the $\stackrel{0}{2}$ lungs in the two groups. In addition all the patients $\underset{x}{x}$ with emphysema had a chronic cough, although in $\frac{0}{7}$ most the volume of sputum expectorated was very. small. While chronic expectoration is not necessarily 0 associated with functional evidence of airway narrowing, it is perhaps surprising that as many as $ᄋ$ four of the emphysematous patients had a normal $D$ conductance-static transpulmonary relationship since the combination of significant intrinsic narrowing of $\bar{N}$ the airways and loss of airway-distending forces would reduce the value of $\Delta$ conductance $/ \Delta$ static $N$ transpulmonary pressure.

We conclude that, during quiet breathing, extrabronchial factors (i.e., loss of airway-distending $\odot$ forces) are often of great importance in the airway $\Phi$ narrowing of patients with radiological and $\stackrel{?}{+}$ functional evidence of emphysema. The recognition $\frac{T}{T}$ of the bronchial and extrabronchial contributions to airflow obstruction is likely to be of more value to $\stackrel{?}{?}$ physicians interested in the pathogenesis of these $\stackrel{\square}{\square}$ common and disabling diseases than to those con- $\bar{\sigma}$ cerned solely with everyday clinical management. 
But the distinction is of practical importance to morbid anatomists using the now standard technique of inflating the lung to a pressure of $25 \mathrm{cmH}_{2} \mathrm{O}$ for post-mortem fixation, since this technique may completely eliminate airway narrowing in the lungs of patients who have suffered during life from airflow obstruction arising from loss of airwaydistending forces.

We are grateful to Dr. George Simon for assessing the chest radiographs, to the patients for their willing cooperation, and to Ann Hart, Patricia Austin, Elizabeth Juniper, and Kanta Patel for technical assistance. This work was aided by grants from the National Fund for Research into Crippling Diseases, the Wates Foundation, and the Tobacco Research Council.

\section{REFERENCES}

Briscoe, W. A. and Nash, E. S. (1965). The slow space in chronic obstructive pulmonary disease. Annals of the New York Academy of Sciences, 121, 706.

Burrows, B., Fletcher, C. M., Heard, B. E., Jones, N. L., and Wootliff, J. S. (1966). The emphysematous and bronchial types of chronic airways obstruction. Lancet, 1,830.

—- Strauss, R. H., and Niden, A. H. (1965). Chronic obstructive lung disease: III Interrelationships of pulmonary function data. American Review of Respiratory Diseases, 91, 861.

Butler, J., Caro, C. G., Alcala, R., and DuBois, A. B. (1960). Physiological factors affecting airway resistance in normal subjects and in patients with obstructive respiratory disease. Journal of Clinical Investigation, 39, 584.

Campbell, E. J. M. and Howell, J. B. L. (1962). Rebreathing method for measurement of mixed venous $\mathrm{PCO}_{2}$. British Medical Journal, 2, 630.

Colebatch, H. J. H., Finucane, K. E., and Smith, M. M. (1973). Pulmonary conductance and elastic recoil relationships in asthma and emphysema. Journal of Applied Physiology, 34, 143.

Cotes, J. E. (1968). Lung Function, 2nd edition. Blackwell, Oxford.

Dayman, H. (1951). Mechanics of airflow in health and in emphysema. Journal of Clinical Investigation, 30, 1175.

Dornhorst, A. C. (1955). Respiratory insufficiency. Lancet, $1,1185$.

DuBois, A. B., Botelho, S. Y., Bedell, G. N., Marshall, R., and Comroe, J. H. Jr. (1956a). A rapid plethysmographic method for measuring thoracic gas volume: a comparison with a nitrogen washout method for measuring functional residual capacity in normal subjects. Journal of Clinical Investigation, 35, 322. $\longrightarrow$ - - and Comroe, J. H. Jr. (1956b). A new method for measuring airway resistance in man using a body plethysmograph: values in normal subjects and in patients with respiratory disease. Journal of Clinical Investigation, 35, 327.

Duffell, G. M., Marcus, J. H., and Ingram, R. H. Jr. (1970). Limitation of expiratory flow in chronic obstructive pulmonary disease. Annals of Internal Medicine, 72, 365.

Fletcher, C. M., Hugh-Jones, P., McNicol, M. W., and Pride, N. B. (1963). The diagnosis of pulmonary emphysema in the presence of chronic bronchitis. Quarterly Journal of Medicine (N.S.), 32, 33.

Hogg, J. C., Macklem, P. T., and Thurlbeck, W. M. (1968). Site and nature of airway obstruction in chronic obstructive lung disease. New England Journal of Medicine, 278, 1355.

Leaver, D. G., Tattersfield, A. E., and Pride, N. B. (1973). Contributions of loss of lung recoil and of enhanced airways collapsibility to the airflow obstruction of chronic bronchitis and emphysema. Journal of Clinical Investigation, 52, 2117.

Matsuba, K. and Thurlbeck, W. M. (1972). The number and dimensions of small airways in emphysematous lungs. American Journal of Pathology, 67, 265.

Mead, J., Takishima, T., and Leith, D. (1970). Stress distribution in lungs: a model of pulmonary elasticity. Journal of Applied Physiology, 28, 596.

, Turner, J. M., Macklem, P. T., and Little, J. B. (1967). Significance of the relationship between lung recoil and maximum expiratory flow. Journal of Applied Physiology, 22, 95.

Milic-Emili, J., Mead, J., Turner, J. M. and Glauser, E. M. (1964). Improved technique for estimating pleural pressure from esophageal balloons. Journal of Applied Physiology, 19, 207.

Miller, D. L., Tinker, C. M., and Fletcher, C. M. (1965). Measurement of sputum volume in factory and office workers. British Medical Journal, 1, 291.

Mitchell, A. S., Vincent, T. N., Ryan, S., and Filley, G. F. (1964). Chronic obstructive bronchopulmonary disease. IV. The clinical and physiological differentiation of chronic bronchitis and emphysema. American Journal of Medical Sciences, 247, 513.

Ogilvie, C. M. (1959). Patterns of disturbed lung function in patients with chronic obstructive vesicular emphysema. Thorax, 14, 113.

, Forster, R. E., Blakemore, W. S., and Morton, J. W. (1957). A standardized breathholding technique for the clinical measurement of the diffusing capacity of the lung for carbon monoxide. Journal of Clinical Investigation, 36, 1.

Penman, R. W. B., O'Neill, R. P., and Begley, L. (1970). Lung elastic recoil and airway resistance as factors limiting forced expiratory flow. American Review of Respiratory Disease, 101, 528. 
Pride, N. B., Permutt, S., Riley, R. L., and BrombergerBarnea, B. (1967). Determinants of maximal expiratory flow from the lungs. Journal of Applied Physiology, 23, 646.

Richards, D. W. (1960). Pulmonary emphysema: etiologic factors and clinical forms. Annals of Internal Medicine, 53, 1105.

Stevens, P. M., Orman, B. F., and Graves, G. (1969). Contributions of lung recoil and airway resistance to forced expiratory flow limitation. American Review of Respiratory Disease, 100, 54.

Stubbs, S. E. and Hyatt, R. E. (1972). Effects of increased lung recoil pressure on maximal expiratory flow in normal subjects. Journal of Applied Physiology, 32, 325.

Requests for reprints to: Dr. N. B. Pride, Department of Medicine, Royal Postgraduate Medical School, Hammersmith Hospital, London W12. 